HIGHLIGHTS OF PRESCRIBING INFORMATION

These highlights do not include all the information needed to use LETAIRIS $^{\circledR}$ safely and effectively. See full prescribing information for LETAIRIS.

Letairis (ambrisentan) tablets, for oral use Initial U.S. Approval: 2007

WARNING: EMBRYO-FETAL TOXICITY
See full prescribing information for complete boxed warning.

- Do not administer Letairis to a pregnant female because it may cause fetal harm $(4.1,5.1,8.1)$.

- Females of reproductive potential: Exclude pregnancy before the start of treatment, monthly during treatment, and 1 month after stopping treatment. Prevent pregnancy during treatment and for one month after stopping treatment by using acceptable methods of contraception $(2.2,8.3)$.

- Because of the risk of embryo-fetal toxicity, for all female patients, Letairis is only available through a restricted program under a Risk Evaluation and Mitigation Strategy (REMS) called the Ambrisentan REMS (5.2).

\section{INDICATIONS AND USAGE.}

Letairis is an endothelin receptor antagonist indicated for the treatment of pulmonary arterial hypertension (PAH) (WHO Group 1):

- To improve exercise ability and delay clinical worsening.

- In combination with tadalafil to reduce the risks of disease progression and hospitalization for worsening $\mathrm{PAH}$, and to improve exercise ability.

Studies establishing effectiveness included trials predominantly in patients with WHO Functional Class II-III symptoms and etiologies of idiopathic or heritable $\mathrm{PAH}(60 \%)$ or $\mathrm{PAH}$ associated with connective tissue diseases (34\%) (1).

\section{DOSAGE AND ADMINISTRATION}

- Initiate treatment at $5 \mathrm{mg}$ once daily (2.1).

- May be started with tadalafil (2.1).

- $\quad$ Titrate at 4-week intervals as needed and tolerated (2.1).

- Do not split, crush, or chew tablets (2.1).
DOSAGE FORMS AND STRENGTHS

Tablet: $5 \mathrm{mg}$ and $10 \mathrm{mg} \mathrm{(3)}$

- Pregnancy (4.1)

- $\quad$ Idiopathic Pulmonary Fibrosis (4.2)

WARNINGS AND PRECAUTIONS

- $\quad$ Fluid retention may require intervention (5.3).

- If patients develop acute pulmonary edema during initiation of therapy with Letairis, consider underlying pulmonary venoocclusive disease and discontinue treatment if necessary (5.4).

- Decreases in sperm count have been observed in patients taking endothelin receptor antagonists (5.5).

- Decreases in hemoglobin have been observed within the first few weeks; measure hemoglobin at initiation, at 1 month, and periodically thereafter (5.6).

\section{ADVERSE REACTIONS}

- Most common adverse reactions (>3\% compared to placebo) are peripheral edema, nasal congestion, sinusitis, and flushing (6.1).

- When used in combination with tadalafil, most common adverse reactions ( $>5 \%$ compared with either monotherapy) are peripheral edema, headache, nasal congestion, cough, anemia, dyspepsia, and bronchitis (6.1)

To report SUSPECTED ADVERSE REACTIONS, contact Gilead Sciences, Inc. at (1-800-445-3235, Option 3) or FDA at 1-800-FDA1088 or www.fda.gov/medwatch.

\section{DRUG INTERACTIONS}

Cyclosporine increases ambrisentan exposure; limit ambrisentan dose to $5 \mathrm{mg}$ once daily (7).

\section{USE IN SPECIFIC POPULATIONS}

- $\quad$ Breastfeeding: Choose Letairis or breastfeeding (8.2).

- $\quad$ Not recommended in patients with moderate or severe hepatic impairment (8.7)

See 17 for PATIENT COUNSELING INFORMATION and Medication Guide.

Revised: 08/2019

\author{
FULL PRESCRIBING INFORMATION: CONTENTS* \\ WARNING: EMBRYO-FETAL TOXICITY \\ 1 INDICATIONS AND USAGE \\ 2 DOSAGE AND ADMINISTRATION \\ 2.1 Adult Dosage \\ 2.2 Pregnancy Testing in Females of Reproductive Potential \\ 3 DOSAGE FORMS AND STRENGTHS \\ 4 CONTRAINDICATIONS \\ 4.1 Pregnancy \\ 4.2 Idiopathic Pulmonary Fibrosis \\ 5 WARNINGS AND PRECAUTIONS \\ 5.1 Embryo-fetal Toxicity \\ 5.2 Ambrisentan Risk Evaluation and Mitigation Strategy (REMS) \\ 5.3 Fluid Retention \\ 5.4 Pulmonary Edema with Pulmonary Veno-occlusive Disease \\ (PVOD) \\ 5.5 Decreased Sperm Counts \\ 5.6 Hematological Changes \\ 6 ADVERSE REACTIONS \\ 6.1 Clinical Trials Experience \\ 6.2 Postmarketing Experience \\ 7 DRUG INTERACTIONS \\ 8 USE IN SPECIFIC POPULATIONS \\ 8.1 Pregnancy
}

8.2 Lactation

8.3 Females and Males of Reproductive Potential

8.4 Pediatric Use

8.5 Geriatric Use

8.6 Renal Impairment

8.7 Hepatic Impairment

10 OVERDOSAGE

11 DESCRIPTION

12 CLINICAL PHARMACOLOGY

12.1 Mechanism of Action

12.2 Pharmacodynamics

12.3 Pharmacokinetics

\section{NONCLINICAL TOXICOLOGY}

13.1 Carcinogenesis, Mutagenesis, Impairment of Fertility 14 CLINICAL STUDIES

14.1 Pulmonary Arterial Hypertension (PAH)

14.2 Combination Treatment of $\mathrm{PAH}$

14.3 Long-term Treatment of PAH

14.4 Adverse Effects in Idiopathic Pulmonary Fibrosis (IPF)

16 HOW SUPPLIED/STORAGE AND HANDLING

17 PATIENT COUNSELING INFORMATION

* Sections or subsections omitted from the full prescribing information are not listed. 


\section{FULL PRESCRIBING INFORMATION}

\section{WARNING: EMBRYO-FETAL TOXICITY}

Do not administer Letairis to a pregnant female because it may cause fetal harm. Letairis is very likely to produce serious birth defects if used by pregnant females, as this effect has been seen consistently when it is administered to animals [see Contraindications (4.1), Warnings and Precautions (5.1), and Use in Specific Populations (8.1)].

Exclude pregnancy before the initiation of treatment with Letairis. Females of reproductive potential must use acceptable methods of contraception during treatment with Letairis and for one month after treatment. Obtain monthly pregnancy tests during treatment and 1 month after discontinuation of treatment [see Dosage and Administration (2.2) and Use in Specific Populations (8.3)].

Because of the risk of embryo-fetal toxicity, for all female patients, Letairis is only available through a restricted program under a Risk Evaluation and Mitigation Strategy (REMS) called the Ambrisentan REMS [see Warnings and Precautions (5.2)].

\section{INDICATIONS AND USAGE}

Letairis is indicated for the treatment of pulmonary arterial hypertension (PAH) (WHO Group 1):

- To improve exercise ability and delay clinical worsening.

- In combination with tadalafil to reduce the risks of disease progression and hospitalization for worsening $\mathrm{PAH}$, and to improve exercise ability [see Clinical Studies (14.2)].

Studies establishing effectiveness included predominantly patients with WHO Functional Class II-III symptoms and etiologies of idiopathic or heritable $\mathrm{PAH}(60 \%)$ or $\mathrm{PAH}$ associated with connective tissue diseases (34\%).

\section{DOSAGE AND ADMINISTRATION}

\subsection{Adult Dosage}

Initiate treatment at $5 \mathrm{mg}$ once daily, with or without tadalafil $20 \mathrm{mg}$ once daily. At 4-week intervals, either the dose of Letairis or tadalafil can be increased, as needed and tolerated, to Letairis $10 \mathrm{mg}$ or tadalafil $40 \mathrm{mg}$.

Do not split, crush, or chew tablets.

\subsection{Pregnancy Testing in Females of Reproductive Potential}

Initiate treatment with Letairis in females of reproductive potential only after a negative pregnancy test. Obtain monthly pregnancy tests during treatment [see Use in Specific Populations (8.3)].

\section{DOSAGE FORMS AND STRENGTHS}

$5 \mathrm{mg}$ and $10 \mathrm{mg}$ film-coated tablets for oral administration

- Each $5 \mathrm{mg}$ tablet is square convex, pale pink, with " 5 " on one side and "GSI" on the other side. 
- Each $10 \mathrm{mg}$ tablet is oval convex, deep pink, with "10" on one side and "GSI" on the other side.

\section{CONTRAINDICATIONS}

\subsection{Pregnancy}

Letairis may cause fetal harm when administered to a pregnant female. Letairis is contraindicated in females who are pregnant. Letairis was consistently shown to have teratogenic effects when administered to animals. If this drug is used during pregnancy, or if the patient becomes pregnant while taking this drug, the patient should be apprised of the potential hazard to a fetus [see Warnings and Precautions $(5.1,5.2)$ and Use in Specific Populations (8.1)].

\subsection{Idiopathic Pulmonary Fibrosis}

Letairis is contraindicated in patients with Idiopathic Pulmonary Fibrosis (IPF), including IPF patients with pulmonary hypertension (WHO Group 3) [see Clinical Studies (14.4)].

\section{WARNINGS AND PRECAUTIONS}

\subsection{Embryo-fetal Toxicity}

Letairis may cause fetal harm when administered during pregnancy and is contraindicated for use in females who are pregnant. In females of reproductive potential, exclude pregnancy prior to initiation of therapy, ensure use of acceptable contraceptive methods, and obtain monthly pregnancy tests [see Dosage and Administration (2.2), and Use in Specific Populations (8.1, 8.3)].

Letairis is only available for females through a restricted program under a REMS [see Warnings and Precautions (5.2)].

\subsection{Ambrisentan Risk Evaluation and Mitigation Strategy (REMS)}

For all females, Letairis is available only through a restricted program under a REMS called the Ambrisentan REMS because of the risk of embryo-fetal toxicity [see Contraindications (4.1), Warnings and Precautions (5.1), and Use in Specific Populations (8.1, 8.3)].

Important requirements of the Ambrisentan REMS include the following:

- Prescribers must be certified with the Ambrisentan REMS by enrolling and completing training.

- All females, regardless of reproductive potential, must enroll in the Ambrisentan REMS prior to initiating Letairis. Male patients are not enrolled in the REMS.

- Females of reproductive potential must comply with the pregnancy testing and contraception requirements [see Use in Specific Populations (8.3)].

- Pharmacies that dispense Letairis must be certified with the Ambrisentan REMS and must dispense to female patients who are authorized to receive Letairis.

Further information is available at www.ambrisentanrems.us.com or 1-888-417-3172. 


\subsection{Fluid Retention}

Peripheral edema is a known class effect of endothelin receptor antagonists, and is also a clinical consequence of $\mathrm{PAH}$ and worsening PAH. In the placebo-controlled studies, there was an increased incidence of peripheral edema in patients treated with doses of 5 or $10 \mathrm{mg}$ Letairis compared to placebo [see Adverse Reactions (6.1)]. Most edema was mild to moderate in severity.

In addition, there have been postmarketing reports of fluid retention in patients with pulmonary hypertension, occurring within weeks after starting Letairis. Patients required intervention with a diuretic, fluid management, or, in some cases, hospitalization for decompensating heart failure.

If clinically significant fluid retention develops, with or without associated weight gain, further evaluation should be undertaken to determine the cause, such as Letairis or underlying heart failure, and the possible need for specific treatment or discontinuation of Letairis therapy.

Peripheral edema/fluid retention is more common with Letairis plus tadalafil than with Letairis or tadalafil alone.

\subsection{Pulmonary Edema with Pulmonary Veno-occlusive Disease (PVOD)}

If patients develop acute pulmonary edema during initiation of therapy with vasodilating agents such as Letairis, the possibility of PVOD should be considered, and if confirmed Letairis should be discontinued.

\subsection{Decreased Sperm Counts}

Decreased sperm counts have been observed in human and animal studies with another endothelin receptor antagonist and in animal fertility studies with ambrisentan. Letairis may have an adverse effect on spermatogenesis. Counsel patients about potential effects on fertility [see Use in Specific Populations (8.6) and Nonclinical Toxicology (13.1)].

\subsection{Hematological Changes}

Decreases in hemoglobin concentration and hematocrit have followed administration of other endothelin receptor antagonists and were observed in clinical studies with Letairis. These decreases were observed within the first few weeks of treatment with Letairis, and stabilized thereafter. The mean decrease in hemoglobin from baseline to end of treatment for those patients receiving Letairis in the 12 -week placebo-controlled studies was $0.8 \mathrm{~g} / \mathrm{dL}$.

Marked decreases in hemoglobin ( $>15 \%$ decrease from baseline resulting in a value below the lower limit of normal) were observed in $7 \%$ of all patients receiving Letairis (and $10 \%$ of patients receiving $10 \mathrm{mg}$ ) compared to $4 \%$ of patients receiving placebo. The cause of the decrease in hemoglobin is unknown, but it does not appear to result from hemorrhage or hemolysis.

In the long-term open-label extension of the two pivotal clinical studies, mean decreases from baseline (ranging from 0.9 to $1.2 \mathrm{~g} / \mathrm{dL}$ ) in hemoglobin concentrations persisted for up to 4 years of treatment.

There have been postmarketing reports of decreases in hemoglobin concentration and hematocrit that have resulted in anemia requiring transfusion.

Measure hemoglobin prior to initiation of Letairis, at one month, and periodically thereafter. Initiation of Letairis therapy is not recommended for patients with clinically significant anemia. If a clinically 
significant decrease in hemoglobin is observed and other causes have been excluded, consider discontinuing Letairis.

\section{ADVERSE REACTIONS}

Clinically significant adverse reactions that appear in other sections of the labeling include:

- Embryo-fetal Toxicity [see Warnings and Precautions (5.1), Use in Specific Populations (8.1)]

- Fluid Retention [see Warnings and Precautions (5.3)]

- Pulmonary Edema with PVOD [see Warnings and Precautions (5.4)]

- Decreased Sperm Count [see Warnings and Precautions (5.5)]

- Hematologic Changes [see Warnings and Precautions (5.6)]

\subsection{Clinical Trials Experience}

Because clinical trials are conducted under widely varying conditions, adverse reaction rates observed in the clinical trials of a drug cannot be directly compared to rates in the clinical trials of another drug and may not reflect the rates observed in practice.

Safety data for Letairis are presented from two 12-week, placebo-controlled studies (ARIES-1 and ARIES-2) in patients with pulmonary arterial hypertension (PAH), and one randomized, double-blind, active-controlled trial in 605 patients with PAH (AMBITION) comparing Letairis plus tadalafil to Letairis or tadalafil alone. The exposure to Letairis in these studies ranged from 1 day to 4 years ( $\mathrm{N}=357$ for at least 6 months and $\mathrm{N}=279$ for at least 1 year).

In ARIES-1 and ARIES-2, a total of 261 patients received Letairis at doses of 2.5, 5, or $10 \mathrm{mg}$ once daily and 132 patients received placebo. The adverse reactions that occurred in $>3 \%$ more patients receiving Letairis than receiving placebo are shown in Table 1.

Table 1 Adverse Reactions with Placebo-Adjusted Rates $>3 \%$ in ARIES-1 and ARIES-2

\begin{tabular}{|l|c|c|c|}
\hline & $\begin{array}{c}\text { Placebo } \\
\text { (N=132) }\end{array}$ & \multicolumn{2}{|c|}{$\begin{array}{c}\text { Letairis } \\
\text { (N=261) }\end{array}$} \\
\hline Adverse Reaction & $\mathbf{n}(\%)$ & $\mathbf{n}(\%)$ & $\begin{array}{c}\text { Placebo-adjusted } \\
\text { (\%) }\end{array}$ \\
\hline Peripheral edema & $14(11)$ & $45(17)$ & 6 \\
\hline Nasal congestion & $2(2)$ & $15(6)$ & 4 \\
\hline Sinusitis & $0(0)$ & $8(3)$ & 3 \\
\hline Flushing & $1(1)$ & $10(4)$ & 3 \\
\hline
\end{tabular}

Most adverse drug reactions were mild to moderate and only nasal congestion was dose-dependent.

Few notable differences in the incidence of adverse reactions were observed for patients by age or sex. Peripheral edema was similar in younger patients $(<65$ years) receiving Letairis $(14 \% ; 29 / 205)$ or placebo (13\%; 13/104), and was greater in elderly patients ( $\geq 65$ years) receiving Letairis $(29 \% ; 16 / 56)$ 
compared to placebo $(4 \% ; 1 / 28)$. The results of such subgroup analyses must be interpreted cautiously.

The incidence of treatment discontinuations due to adverse events other than those related to PAH during the clinical trials in patients with PAH was similar for Letairis $(2 \% ; 5 / 261$ patients) and placebo (2\%; $3 / 132$ patients). The incidence of patients with serious adverse events other than those related to $\mathrm{PAH}$ during the clinical trials in patients with $\mathrm{PAH}$ was similar for placebo (7\%; $9 / 132$ patients) and for Letairis ( $5 \%$; $13 / 261$ patients).

During 12-week controlled clinical trials, the incidence of aminotransferase elevations $>3 \times$ upper limit of normal (ULN) were $0 \%$ on Letairis and $2.3 \%$ on placebo. In practice, cases of hepatic injury should be carefully evaluated for cause.

\section{Combination Use with Tadalafil}

The mean exposure to Letairis + tadalafil in the AMBITION study was 78.7 weeks. The adverse reactions that occurred in $>5 \%$ more patients receiving Letairis + tadalafil than receiving Letairis or tadalafil monotherapy in AMBITION are shown in Table 2.

Table 2 Adverse Reactions Reported More Commonly (>5\%) on Letairis + Tadalafil than on Letairis or Tadalafil Monotherapy (ITT) in AMBITION

\begin{tabular}{|l|c|c|c|}
\hline Adverse Reactions & $\begin{array}{c}\text { Letairis + Tadalafil } \\
\text { Combination Therapy } \\
\mathbf{( N = 3 0 2 )}\end{array}$ & $\begin{array}{c}\text { Letairis } \\
\text { Monotherapy } \\
\mathbf{n}(\mathbf{N}=\mathbf{1 5 2 )} \\
\mathbf{n}(\%)\end{array}$ & $\begin{array}{c}\text { Tadalafil } \\
\text { Monotherapy } \\
\mathbf{( N = 1 5 1 )}\end{array}$ \\
\hline Peripheral edema & $135(45 \%)$ & $58(38 \%)$ & $43(28 \%)$ \\
\hline Headache & $125(41 \%)$ & $51(34 \%)$ & $53(35 \%)$ \\
\hline Nasal congestion & $58(19 \%)$ & $25(16 \%)$ & $17(11 \%)$ \\
\hline Cough & $53(18 \%)$ & $20(13 \%)$ & $24(16 \%)$ \\
\hline Anemia & $44(15 \%)$ & $11(7 \%)$ & $17(11 \%)$ \\
\hline Dyspepsia & $32(11 \%)$ & $5(3 \%)$ & $18(12 \%)$ \\
\hline Bronchitis & $31(10 \%)$ & $6(4 \%)$ & $13(9 \%)$ \\
\hline
\end{tabular}

Peripheral edema was more frequent on combination therapy; however, there was no notable difference observed in the incidence of peripheral edema in elderly patients ( $\geq 65$ years) versus younger patients ( $<65$ years) on combination therapy $(44 \%$ vs. $45 \%)$ or Letairis monotherapy $(37 \%$ vs. $39 \%)$ in AMBITION.

Treatment discontinuations due to adverse events while on randomized treatment were similar across treatment groups: $16 \%$ for Letairis + tadalafil, $14 \%$ for Letairis alone, and $13 \%$ for tadalafil alone.

\section{Use in Patients with Prior Endothelin Receptor Antagonist (ERA) Related Serum Liver Enzyme}

\section{Abnormalities}

In an uncontrolled, open-label study, 36 patients who had previously discontinued endothelin receptor antagonists (ERAs: bosentan, an investigational drug, or both) due to aminotransferase elevations $>3$ $x$ ULN were treated with Letairis. Prior elevations were predominantly moderate, with $64 \%$ of the ALT 
elevations $<5 \times$ ULN, but 9 patients had elevations $>8 \times$ ULN. Eight patients had been re-challenged with bosentan and/or the investigational ERA and all eight had a recurrence of aminotransferase abnormalities that required discontinuation of ERA therapy. All patients had to have normal aminotransferase levels on entry to this study. Twenty-five of the 36 patients were also receiving prostanoid and/or phosphodiesterase type 5 (PDE5) inhibitor therapy. Two patients discontinued early (including one of the patients with a prior $8 \times$ ULN elevation). Of the remaining 34 patients, one patient experienced a mild aminotransferase elevation at 12 weeks on Letairis $5 \mathrm{mg}$ that resolved with decreasing the dosage to $2.5 \mathrm{mg}$, and that did not recur with later escalations to $10 \mathrm{mg}$. With a median follow-up of 13 months and with $50 \%$ of patients increasing the dose of Letairis to $10 \mathrm{mg}$, no patients were discontinued for aminotransferase elevations. While the uncontrolled study design does not provide information about what would have occurred with re-administration of previously used ERAs or show that Letairis led to fewer aminotransferase elevations than would have been seen with those drugs, the study indicates that Letairis may be tried in patients who have experienced asymptomatic aminotransferase elevations on other ERAs after aminotransferase levels have returned to normal.

\subsection{Postmarketing Experience}

The following adverse reactions were identified during post-approval use of Letairis. Because these reactions were reported voluntarily from a population of uncertain size, it is not possible to estimate reliably the frequency or to establish a causal relationship to drug exposure: anemia requiring transfusion [see Warnings and Precautions (5.6)] heart failure (associated with fluid retention), symptomatic hypotension, and hypersensitivity (e.g., angioedema, rash).

Elevations of liver aminotransferases (ALT, AST) have been reported with Letairis use; in most cases alternative causes of the liver injury could be identified (heart failure, hepatic congestion, hepatitis, alcohol use, hepatotoxic medications). Other endothelin receptor antagonists have been associated with elevations of aminotransferases, hepatotoxicity, and cases of liver failure [see Adverse Reactions (6.1)].

\section{DRUG INTERACTIONS}

Multiple dose coadministration of ambrisentan and cyclosporine resulted in an approximately 2-fold increase in ambrisentan exposure in healthy volunteers; therefore, limit the dose of ambrisentan to 5 mg once daily when coadministered with cyclosporine [see Clinical Pharmacology (12.3)].

\section{USE IN SPECIFIC POPULATIONS}

\subsection{Pregnancy}

\section{$\underline{\text { Risk Summary }}$}

Based on data from animal reproduction studies, Letairis may cause fetal harm when administered to a pregnant woman and is contraindicated during pregnancy. There are limited data on Letairis use in pregnant women. In animal reproduction studies, Letairis was teratogenic in rats and rabbits at doses which resulted in exposures of 3.5 and 1.7 times, respectively, the human dose of $10 \mathrm{mg}$ per day [see Animal Data]. If this drug is used during pregnancy, or if the patient becomes pregnant while taking this drug, advise the patient of the potential hazard to a fetus [see Contraindications (4.1), Warnings and Precautions (5.1)].

The estimated background risk of major birth defects and miscarriage for the indicated population is unknown. All pregnancies have a background risk of birth defect, loss, or other adverse outcomes. In 
the U.S. general population, the estimated background risk of major birth defects and miscarriage in clinically recognized pregnancies is $2-4 \%$ and $15-20 \%$, respectively.

Data

\section{Animal Data}

Letairis was teratogenic at oral dosages of $\geq 15 \mathrm{mg} / \mathrm{kg} /$ day (AUC $51.7 \mathrm{~h} \cdot \mu \mathrm{g} / \mathrm{mL}$ ) in rats and $\geq 7$ $\mathrm{mg} / \mathrm{kg} / \mathrm{day}(24.7 \mathrm{~h} \cdot \mu \mathrm{g} / \mathrm{mL})$ in rabbits; it was not studied at lower dosages. These dosages are of 3.5 and 1.7 times, respectively, the human dose of $10 \mathrm{mg}$ per day $(14.8 \mathrm{~h} \cdot \mu \mathrm{g} / \mathrm{mL})$ based on AUC. In both species, there were abnormalities of the lower jaw and hard and soft palate, malformation of the heart and great vessels, and failure of formation of the thymus and thyroid.

A preclinical study in rats has shown decreased survival of newborn pups (mid and high dosages) and effects on testicle size and fertility of pups (high dosage) following maternal treatment with ambrisentan from late gestation through weaning. The mid and high dosages were $51 \mathrm{x}$, and $170 \mathrm{x}$ (on a $\mathrm{mg} / \mathrm{m}^{2}$ body surface area basis) the maximum oral human dose of $10 \mathrm{mg}$ and an average adult body weight of $70 \mathrm{~kg}$. These effects were absent at a maternal dosage $17 \mathrm{x}$ the human dose based on $\mathrm{mg} / \mathrm{m}^{2}$.

\subsection{Lactation}

\section{Risk Summary}

It is not known whether ambrisentan is present in human milk. Because many drugs are present in human milk and because of the potential for serious adverse reactions in breastfed infants from Letairis, a decision should be made whether to discontinue breastfeeding or discontinue Letairis, taking into account the importance of the drug to the mother.

\subsection{Females and Males of Reproductive Potential}

\section{Pregnancy Testing}

Female patients of reproductive potential must have a negative pregnancy test prior to initiation of treatment, monthly pregnancy test during treatment, and pregnancy test 1 month after stopping treatment with Letairis. Advise patients to contact their healthcare provider if they become pregnant or suspect they may be pregnant. Perform a pregnancy test if pregnancy is suspected for any reason. For positive pregnancy tests, counsel patient on the potential risk to the fetus and patient options [see Boxed Warning and Dosage and Administration (2.2)].

\section{Contraception}

Female patients of reproductive potential must use acceptable methods of contraception during treatment with Letairis and for 1 month after stopping treatment with Letairis. Patients may choose one highly effective form of contraception (intrauterine device [IUD], contraceptive implant, or tubal sterilization) or a combination of methods (hormone method with a barrier method or two barrier methods). If a partner's vasectomy is the chosen method of contraception, a hormone or barrier method must be used along with this method. Counsel patients on pregnancy planning and prevention, including emergency contraception, or designate counseling by another healthcare provider trained in contraceptive counseling [see Boxed Warning]. 


\section{Males}

In a 6-month study of another endothelin receptor antagonist, bosentan, 25 male patients with WHO functional class III and IV PAH and normal baseline sperm count were evaluated for effects on testicular function. There was a decline in sperm count of at least $50 \%$ in $25 \%$ of the patients after 3 or 6 months of treatment with bosentan. One patient developed marked oligospermia at 3 months, and the sperm count remained low with 2 follow-up measurements over the subsequent 6 weeks. Bosentan was discontinued and after 2 months the sperm count had returned to baseline levels. In 22 patients who completed 6 months of treatment, sperm count remained within the normal range and no changes in sperm morphology, sperm motility, or hormone levels were observed. Based on these findings and preclinical data [see Nonclinical Toxicology (13.1)] from endothelin receptor antagonists, it cannot be excluded that endothelin receptor antagonists such as Letairis have an adverse effect on spermatogenesis. Counsel patients about the potential effects on fertility [see Warnings and Precautions (5.5)].

\subsection{Pediatric Use}

Safety and effectiveness of Letairis in pediatric patients have not been established.

Juvenile Animal Data

In juvenile rats administered ambrisentan orally once daily during postnatal day 7 to 26,36 , or 62 , a decrease in brain weight $(-3 \%$ to $-8 \%)$ with no morphologic or neurobehavioral changes occurred after breathing sounds, apnea, and hypoxia were observed, at exposures approximately 1.8 to 7.0 times human pediatric exposures at $10 \mathrm{mg}$, based on AUC.

\subsection{Geriatric Use}

In the two placebo-controlled clinical studies of Letairis, $21 \%$ of patients were $\geq 65$ years old and $5 \%$ were $\geq 75$ years old. The elderly (age $\geq 65$ years) showed less improvement in walk distances with Letairis than younger patients did, but the results of such subgroup analyses must be interpreted cautiously. Peripheral edema was more common in the elderly than in younger patients.

\subsection{Renal Impairment}

The impact of renal impairment on the pharmacokinetics of ambrisentan has been examined using a population pharmacokinetic approach in $\mathrm{PAH}$ patients with creatinine clearances ranging between 20 and $150 \mathrm{~mL} / \mathrm{min}$. There was no significant impact of mild or moderate renal impairment on exposure to ambrisentan [see Clinical Pharmacology (12.3)]. Dose adjustment of Letairis in patients with mild or moderate renal impairment is therefore not required. There is no information on the exposure to ambrisentan in patients with severe renal impairment.

The impact of hemodialysis on the disposition of ambrisentan has not been investigated.

\subsection{Hepatic Impairment}

\section{Pre-existing Hepatic Impairment}

The influence of pre-existing hepatic impairment on the pharmacokinetics of ambrisentan has not been evaluated. Because there is in vitro and in vivo evidence of significant metabolic and biliary contribution to the elimination of ambrisentan, hepatic impairment might be expected to have 
significant effects on the pharmacokinetics of ambrisentan [see Clinical Pharmacology (12.3)]. Letairis is not recommended in patients with moderate or severe hepatic impairment. There is no information on the use of Letairis in patients with mild pre-existing impaired liver function; however, exposure to ambrisentan may be increased in these patients.

\section{Elevation of Liver Transaminases}

Other endothelin receptor antagonists (ERAs) have been associated with aminotransferase (AST, ALT) elevations, hepatotoxicity, and cases of liver failure [see Adverse Reactions (6.1, 6.2)]. In patients who develop hepatic impairment after Letairis initiation, the cause of liver injury should be fully investigated. Discontinue Letairis if elevations of liver aminotransferases are $>5 \times$ ULN or if elevations are accompanied by bilirubin $>2 \times U L N$, or by signs or symptoms of liver dysfunction and other causes are excluded.

\section{OVERDOSAGE}

There is no experience with overdosage of Letairis. The highest single dose of Letairis administered to healthy volunteers was $100 \mathrm{mg}$, and the highest daily dose administered to patients with PAH was $10 \mathrm{mg}$ once daily. In healthy volunteers, single doses of $50 \mathrm{mg}$ and $100 \mathrm{mg}$ (5 to 10 times the maximum recommended dose) were associated with headache, flushing, dizziness, nausea, and nasal congestion. Massive overdosage could potentially result in hypotension that may require intervention.

\section{DESCRIPTION}

Letairis is the brand name for ambrisentan, an endothelin receptor antagonist that is selective for the endothelin type-A $\left(E T_{A}\right)$ receptor. The chemical name of ambrisentan is

(+)-(2S)-2-[(4,6-dimethylpyrimidin-2-yl)oxy]-3-methoxy-3,3-diphenylpropanoic acid. It has a molecular formula of $\mathrm{C}_{22} \mathrm{H}_{22} \mathrm{~N}_{2} \mathrm{O}_{4}$ and a molecular weight of 378.42 . It contains a single chiral center determined to be the $(S)$ configuration and has the following structural formula:

\section{Figure 1 Ambrisentan Structural Formula}

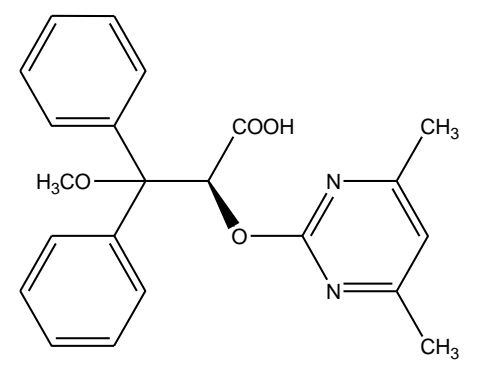

Ambrisentan is a white to off-white, crystalline solid. It is a carboxylic acid with a pKa of 4.0. Ambrisentan is practically insoluble in water and in aqueous solutions at low pH. Solubility increases in aqueous solutions at higher $\mathrm{pH}$. In the solid state ambrisentan is very stable, is not hygroscopic, and is not light sensitive.

Letairis is available as $5 \mathrm{mg}$ and $10 \mathrm{mg}$ film-coated tablets for once daily oral administration. The tablets include the following inactive ingredients: croscarmellose sodium, lactose monohydrate, magnesium stearate and microcrystalline cellulose. The tablets are film-coated with a coating material containing FD\&C Red \#40 aluminum lake, lecithin, polyethylene glycol, polyvinyl alcohol, talc, and titanium dioxide. Each square, pale pink Letairis tablet contains $5 \mathrm{mg}$ of ambrisentan. Each oval, deep pink Letairis tablet contains $10 \mathrm{mg}$ of ambrisentan. Letairis tablets are unscored. 


\section{CLINICAL PHARMACOLOGY}

\subsection{Mechanism of Action}

Endothelin-1 (ET-1) is a potent autocrine and paracrine peptide. Two receptor subtypes, $E T_{A}$ and $\mathrm{ET}_{\mathrm{B}}$, mediate the effects of ET-1 in the vascular smooth muscle and endothelium. The primary actions of $E T_{A}$ are vasoconstriction and cell proliferation, while the predominant actions of $E T_{B}$ are vasodilation, antiproliferation, and ET-1 clearance.

In patients with PAH, plasma ET-1 concentrations are increased as much as 10 -fold and correlate with increased mean right atrial pressure and disease severity. ET-1 and ET-1 mRNA concentrations are increased as much as 9-fold in the lung tissue of patients with PAH, primarily in the endothelium of pulmonary arteries. These findings suggest that ET-1 may play a critical role in the pathogenesis and progression of $\mathrm{PAH}$.

Ambrisentan is a high-affinity $\left(K_{i}=0.011 \mathrm{nM}\right) \mathrm{ET}_{\mathrm{A}}$ receptor antagonist with a high selectivity for the $\mathrm{ET}_{\mathrm{A}}$ versus $\mathrm{ET}_{\mathrm{B}}$ receptor (>4000-fold). The clinical impact of high selectivity for $\mathrm{ET}_{\mathrm{A}}$ is not known.

\subsection{Pharmacodynamics}

\section{Cardiac Electrophysiology}

In a randomized, positive- and placebo-controlled, parallel-group study, healthy subjects received either Letairis $10 \mathrm{mg}$ daily followed by a single dose of $40 \mathrm{mg}$, placebo followed by a single dose of moxifloxacin $400 \mathrm{mg}$, or placebo alone. Letairis $10 \mathrm{mg}$ daily had no significant effect on the QTc interval. The $40 \mathrm{mg}$ dose of Letairis increased mean QTc at $t_{\max }$ by $5 \mathrm{~ms}$ with an upper $95 \%$ confidence limit of $9 \mathrm{~ms}$. For patients receiving Letairis 5-10 mg daily and not taking metabolic inhibitors, no significant QT prolongation is expected.

\section{N-terminal pro-B-type natriuretic peptide (NT-proBNP)}

In AMBITION [see Clinical Studies (14.2)], the decrease in NT-proBNP in patients on Letairis plus tadalafil was observed early (Week 4 ) and was sustained, with a reduction of $63 \%$ on Letairis plus tadalafil, $50 \%$ on Letairis alone, and $41 \%$ on tadalafil alone at Week 24.

\subsection{Pharmacokinetics}

The pharmacokinetics of ambrisentan (S-ambrisentan) in healthy subjects is dose proportional. The absolute bioavailability of ambrisentan is not known. Ambrisentan is absorbed with peak concentrations occurring approximately 2 hours after oral administration in healthy subjects and PAH patients. Food does not affect its bioavailability. In vitro studies indicate that ambrisentan is a substrate of P-gp. Ambrisentan is highly bound to plasma proteins (99\%). The elimination of ambrisentan is predominantly by non-renal pathways, but the relative contributions of metabolism and biliary elimination have not been well characterized. In plasma, the AUC of 4-hydroxymethyl ambrisentan accounts for approximately $4 \%$ relative to parent ambrisentan AUC. The in vivo inversion of S-ambrisentan to R-ambrisentan is negligible. The mean oral clearance of ambrisentan is $38 \mathrm{~mL} / \mathrm{min}$ and $19 \mathrm{~mL} / \mathrm{min}$ in healthy subjects and in PAH patients, respectively. Although ambrisentan has a 15-hour terminal half-life, the mean trough concentration of ambrisentan at steady-state is about $15 \%$ of the mean peak concentration and the accumulation factor is about 1.2 after long-term daily dosing, indicating that the effective half-life of ambrisentan is about 9 hours. 


\section{Drug Interactions}

\section{In Vitro Studies}

Studies with human liver tissue indicate that ambrisentan is metabolized by CYP3A, CYP2C19, and uridine 5'-diphosphate glucuronosyltransferases (UGTs) 1A9S, 2B7S, and 1A3S. In vitro studies suggest that ambrisentan is a substrate of the Organic Anion Transporting Polypeptides OATP1B1 and OATP1B3, and P-glycoprotein (P-gp). Drug interactions might be expected because of these factors; however, a clinically relevant interaction has been demonstrated only with cyclosporine [see Drug Interactions (7)]. In vitro studies found ambrisentan to have little to no inhibition of human hepatic transporters. Ambrisentan demonstrated weak dose-dependent inhibition of OATP1B1, OATP1B3, and NTCP ( $\mathrm{IC}_{50}$ of $47 \mu \mathrm{M}, 45 \mu \mathrm{M}$, and approximately $100 \mu \mathrm{M}$, respectively) and no transporter-specific inhibition of BSEP, BRCP, P-gp, or MRP2. Ambrisentan does not inhibit or induce drug metabolizing enzymes at clinically relevant concentrations.

\section{In Vivo Studies}

The effects of other drugs on ambrisentan pharmacokinetics and the effects of ambrisentan on the exposure to other drugs are shown in Figure 2 and Figure 3, respectively. 
Figure 2 Effects of Other Drugs on Ambrisentan Pharmacokinetics

Interacting Drug

Cyclosporine

Mycophenolate Mofetil

Ketoconazole

Omeprazole*

Rifampin**

Ritonavir

Tacrolimus
Sildenafil
Cmax

Tadalafil

Warfarin

PK

Fold Change and 90\% CI

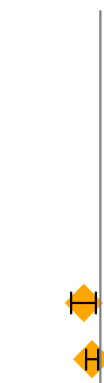

AUC

Cmax

AUC

Cmax

AUC

Cmax

AUC

Cmax

AUC

Cmax

AUC

Cmax

Cmax

Cmax

AUC
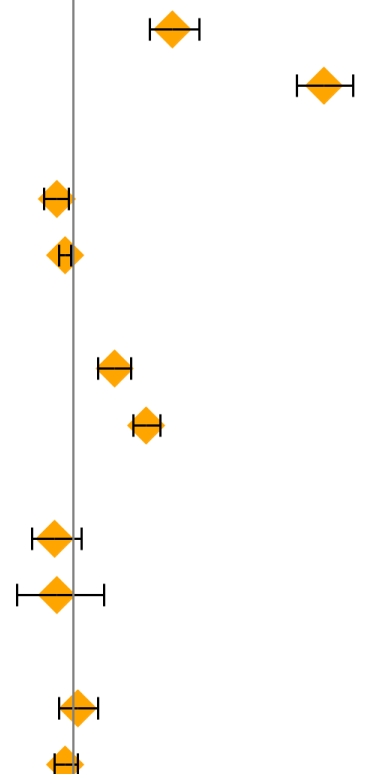

H

$0.0 \quad 0.5$

Change relative to ambrisentan alone
No dose adjustment

No dose adjustment

No dose adjustment

No dose adjustment

No dose adjustment

Limit ambrisentan to

$5 \mathrm{mg}$ once daily

No dose adjustment

No dose adjustment

No dose adjustment

No dose adjustment ra

* Omeprazole: based on population pharmacokinetic analysis in PAH patients

** Rifampin: AUC and $\mathrm{C}_{\max }$ were measured at steady-state. On Day 3 of coadministration a transient 2-fold increase in AUC was noted that was no longer evident by Day 7 . Day 7 results are presented. 
Figure 3 Effects of Ambrisentan on Other Drugs

Interacting Drug

Cyclosporine

Digoxin

Ethinylestradiol

Norethindrone

Mycophenolic acid*

Ritonavir

Sildenafil

- Desmethylsildenafil

Warfarin

- S-Warfarin

- R-Warfarin
PK

Cmax

AUC

Cmax

AUC

Cmax

AUC

Cmax

AUC

Cmax

AUC

Cmax

AUC

Cmax

AUC

Cmax

AUC

Tadalafil

Cmax

AUC

$\operatorname{Emax}_{* *}$

AUEC**

Cmax

AUC

Cmax

AUC
Fold Change and 90\% CI

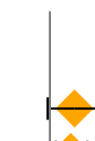

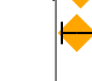

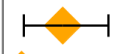

$\gamma$

$\theta$

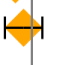

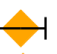

$\mapsto$

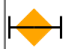

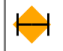
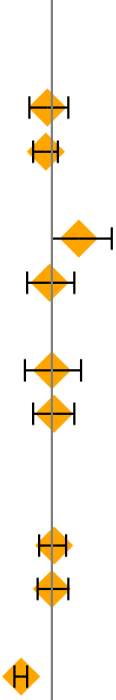

$H$

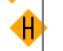

$H$

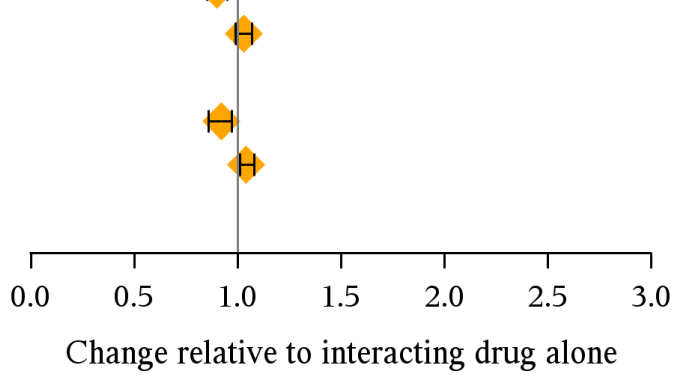

Recommendation

No dose adjustment

No dose adjustment

No dose adjustment

No dose adjustment

No dose adjustment

No dose adjustment

No dose adjustment

No dose adjustment

No dose adjustment

* Active metabolite of mycophenolate mofetil

** GMR $(95 \% \mathrm{Cl})$ for INR 


\section{NONCLINICAL TOXICOLOGY}

\subsection{Carcinogenesis, Mutagenesis, Impairment of Fertility}

Oral carcinogenicity studies of up to two years duration were conducted at starting doses of 10,30 , and $60 \mathrm{mg} / \mathrm{kg} / \mathrm{day}$ in rats (8 to 48 times the maximum recommended human dose [MRHD] on a $\mathrm{mg} / \mathrm{m}^{2}$ basis) and at 50,150, and $250 \mathrm{mg} / \mathrm{kg} /$ day in mice (28 to 140 times the MRHD). In the rat study, the high- and mid-dose male and female groups had their doses lowered to 40 and 20 $\mathrm{mg} / \mathrm{kg} /$ day, respectively, in week 51 because of effects on survival. The high-dose males and females were taken off drug completely in weeks 69 and 93, respectively. The only evidence of ambrisentan-related carcinogenicity was a positive trend in male rats, for the combined incidence of benign basal cell tumor and basal cell carcinoma of skin/subcutis in the mid-dose group (high-dose group excluded from analysis), and the occurrence of mammary fibroadenomas in males in the high-dose group. In the mouse study, high-dose male and female groups had their doses lowered to $150 \mathrm{mg} / \mathrm{kg} / \mathrm{day}$ in week 39 and were taken off drug completely in week 96 (males) or week 76 (females). In mice, ambrisentan was not associated with excess tumors in any dosed group.

Positive findings of clastogenicity were detected, at drug concentrations producing moderate to high toxicity, in the chromosome aberration assay in cultured human lymphocytes. There was no evidence for genetic toxicity of ambrisentan when tested in vitro in bacteria (Ames test) or in vivo in rats (micronucleus assay, unscheduled DNA synthesis assay).

The development of testicular tubular atrophy and impaired fertility has been linked to the chronic administration of endothelin receptor antagonists in rodents. Testicular tubular degeneration was observed in rats treated with ambrisentan for two years at doses $\geq 10 \mathrm{mg} / \mathrm{kg} /$ day (8-fold MRHD). Increased incidences of testicular findings were also observed in mice treated for two years at doses $\geq 50 \mathrm{mg} / \mathrm{kg} / \mathrm{day}$ (28-fold MRHD). Effects on sperm count, sperm morphology, mating performance, and fertility were observed in fertility studies in which male rats were treated with ambrisentan at oral doses of $300 \mathrm{mg} / \mathrm{kg} / \mathrm{day}$ (236-fold MRHD). At doses of $\geq 10 \mathrm{mg} / \mathrm{kg} /$ day, observations of testicular histopathology in the absence of fertility and sperm effects were also present.

\section{CLINICAL STUDIES}

\subsection{Pulmonary Arterial Hypertension (PAH)}

Two 12-week, randomized, double-blind, placebo-controlled, multicenter studies were conducted in 393 patients with PAH (WHO Group 1). The two studies were identical in design except for the doses of Letairis and the geographic region of the investigational sites. ARIES-1 compared once-daily doses of $5 \mathrm{mg}$ and $10 \mathrm{mg}$ Letairis to placebo, while ARIES-2 compared once-daily doses of $2.5 \mathrm{mg}$ and 5 mg Letairis to placebo. In both studies, Letairis or placebo was added to current therapy, which could have included a combination of anticoagulants, diuretics, calcium channel blockers, or digoxin, but not epoprostenol, treprostinil, iloprost, bosentan, or sildenafil. The primary study endpoint was 6 -minute walk distance. In addition, clinical worsening, WHO functional class, dyspnea, and SF-36 ${ }^{\circledR}$ Health Survey were assessed.

Patients had idiopathic or heritable PAH (64\%) or PAH associated with connective tissue diseases $(32 \%)$, HIV infection (3\%), or anorexigen use (1\%). There were no patients with PAH associated with congenital heart disease.

Patients had WHO functional class I (2\%), II (38\%), III (55\%), or IV (5\%) symptoms at baseline. The mean age of patients was 50 years, $79 \%$ of patients were female, and $77 \%$ were Caucasian. 


\section{Submaximal Exercise Ability}

Results of the 6 -minute walk distance at 12 weeks for the ARIES-1 and ARIES-2 studies are shown in Table 3 and Figure 4.

Table 3 Changes from Baseline in 6-Minute Walk Distance (meters) (ARIES-1 and ARIES-2)

\begin{tabular}{|c|c|c|c|c|c|c|}
\hline & \multicolumn{3}{|c|}{ ARIES-1 } & \multicolumn{3}{|c|}{ ARIES-2 } \\
\hline & $\begin{array}{l}\text { Placebo } \\
(\mathrm{N}=67)\end{array}$ & $\begin{array}{c}5 \mathrm{mg} \\
(\mathrm{N}=67)\end{array}$ & $\begin{array}{l}10 \mathrm{mg} \\
(\mathrm{N}=67)\end{array}$ & $\begin{array}{c}\text { Placebo } \\
(\mathrm{N}=65)\end{array}$ & $\begin{array}{l}2.5 \mathrm{mg} \\
(\mathrm{N}=64)\end{array}$ & $\begin{array}{c}5 \mathrm{mg} \\
(\mathrm{N}=63)\end{array}$ \\
\hline Baseline & $342 \pm 73$ & $340 \pm 77$ & $342 \pm 78$ & $343 \pm 86$ & $347 \pm 84$ & $355 \pm 84$ \\
\hline $\begin{array}{l}\text { Mean change } \\
\text { from baseline }\end{array}$ & $-8 \pm 79$ & $23 \pm 83$ & $44 \pm 63$ & $-10 \pm 94$ & $22 \pm 83$ & $49 \pm 75$ \\
\hline $\begin{array}{l}\text { Placebo-adjusted } \\
\text { mean change } \\
\text { from baseline }\end{array}$ & - & 31 & 51 & - & 32 & 59 \\
\hline $\begin{array}{l}\text { Placebo-adjusted } \\
\text { median change } \\
\text { from baseline }\end{array}$ & - & 27 & 39 & - & 30 & 45 \\
\hline$p$-value ${ }^{a}$ & - & 0.008 & $<0.001$ & - & 0.022 & $<0.001$ \\
\hline
\end{tabular}

Mean \pm standard deviation

a $p$-values are Wilcoxon rank sum test comparisons of Letairis to placebo at Week 12 stratified by idiopathic or heritable PAH and non-idiopathic, non-heritable $\mathrm{PAH}$ patients 


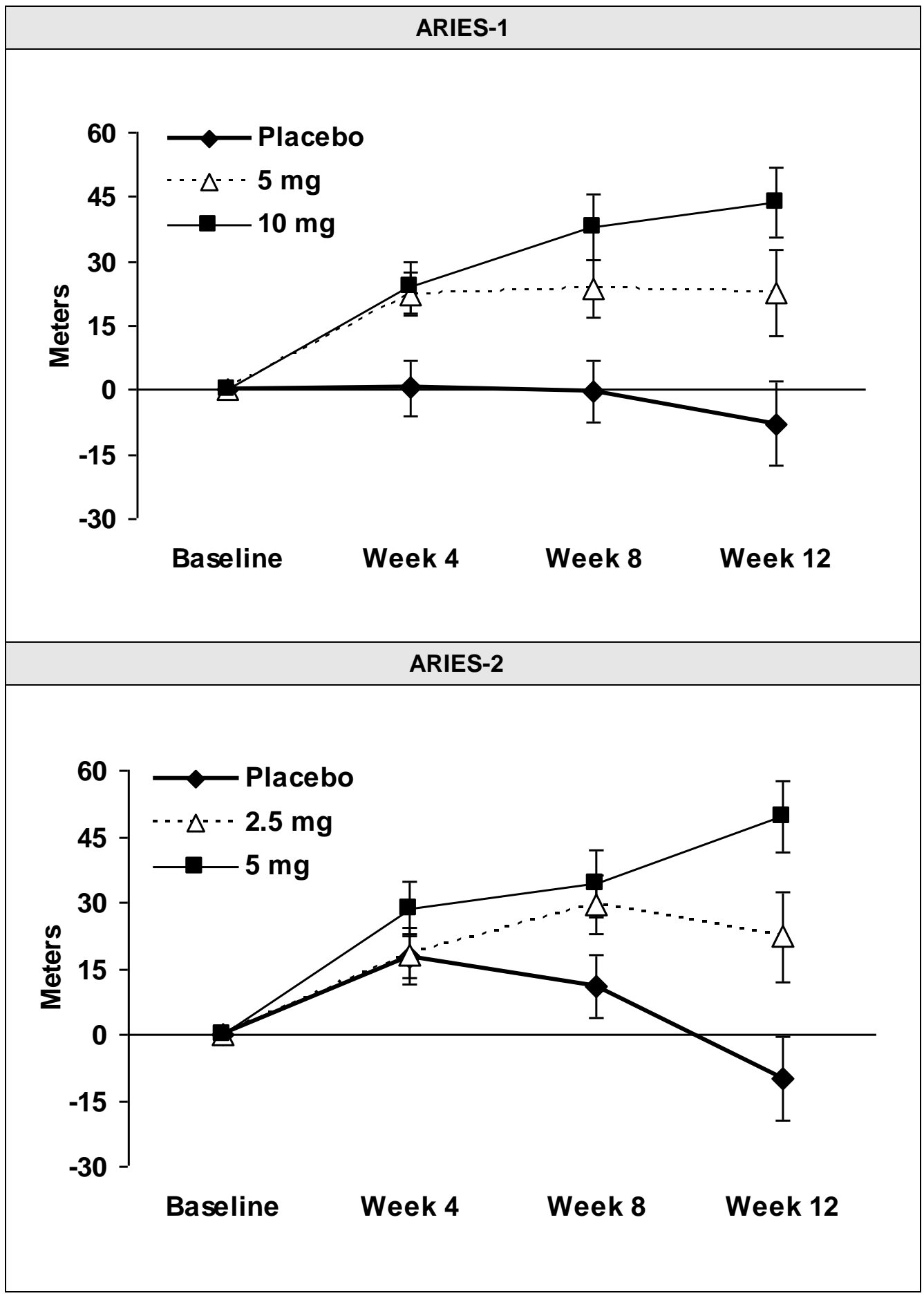

Mean change from baseline in 6-minute walk distance in the placebo and Letairis groups. Values are expressed as mean \pm standard error of the mean.

In both studies, treatment with Letairis resulted in a significant improvement in 6-minute walk distance for each dose of Letairis and the improvements increased with dose. An increase in 6-minute walk distance was observed after 4 weeks of treatment with Letairis, with a dose-response observed after 12 weeks of treatment. Improvements in walk distance with Letairis were smaller for elderly patients (age $\geq 65$ ) than younger patients and for patients with secondary PAH than for patients with idiopathic or heritable PAH. The results of such subgroup analyses must be interpreted cautiously. 


\section{Clinical Worsening}

Time to clinical worsening of PAH was defined as the first occurrence of death, lung transplantation, hospitalization for $\mathrm{PAH}$, atrial septostomy, study withdrawal due to the addition of other $\mathrm{PAH}$ therapeutic agents, or study withdrawal due to early escape. Early escape was defined as meeting two or more of the following criteria: a $20 \%$ decrease in the 6-minute walk distance; an increase in WHO functional class; worsening right ventricular failure; rapidly progressing cardiogenic, hepatic, or renal failure; or refractory systolic hypotension. The clinical worsening events during the 12-week treatment period of the Letairis clinical trials are shown in Table 4 and Figure 5.

Table 4 Time to Clinical Worsening (ARIES-1 and ARIES-2)

\begin{tabular}{|l|c|c|c|c|}
\hline \multirow{2}{*}{} & \multicolumn{2}{|c|}{ ARIES-1 } & \multicolumn{2}{c|}{ ARIES-2 } \\
\cline { 2 - 5 } & $\begin{array}{c}\text { Placebo } \\
\mathbf{( N = 6 7 )}\end{array}$ & $\begin{array}{c}\text { Letairis } \\
\mathbf{( N = 1 3 4 )}\end{array}$ & $\begin{array}{c}\text { Placebo } \\
\mathbf{( N = 6 5 )}\end{array}$ & $\begin{array}{c}\text { Letairis } \\
\mathbf{( N = 1 2 7 )}\end{array}$ \\
\hline Clinical worsening, no. (\%) & $7(10 \%)$ & $4(3 \%)$ & $13(22 \%)$ & $8(6 \%)$ \\
\hline Hazard ratio & - & 0.28 & - & 0.30 \\
\hline p-value, Log-rank test & - & 0.030 & - & 0.005 \\
\hline
\end{tabular}

Intention-to-treat population.

Note: Patients may have had more than one reason for clinical worsening.

Nominal p-values

There was a significant delay in the time to clinical worsening for patients receiving Letairis compared to placebo. Results in subgroups such as the elderly were also favorable. 
Figure 5 Time to Clinical Worsening (ARIES-1 and ARIES-2)

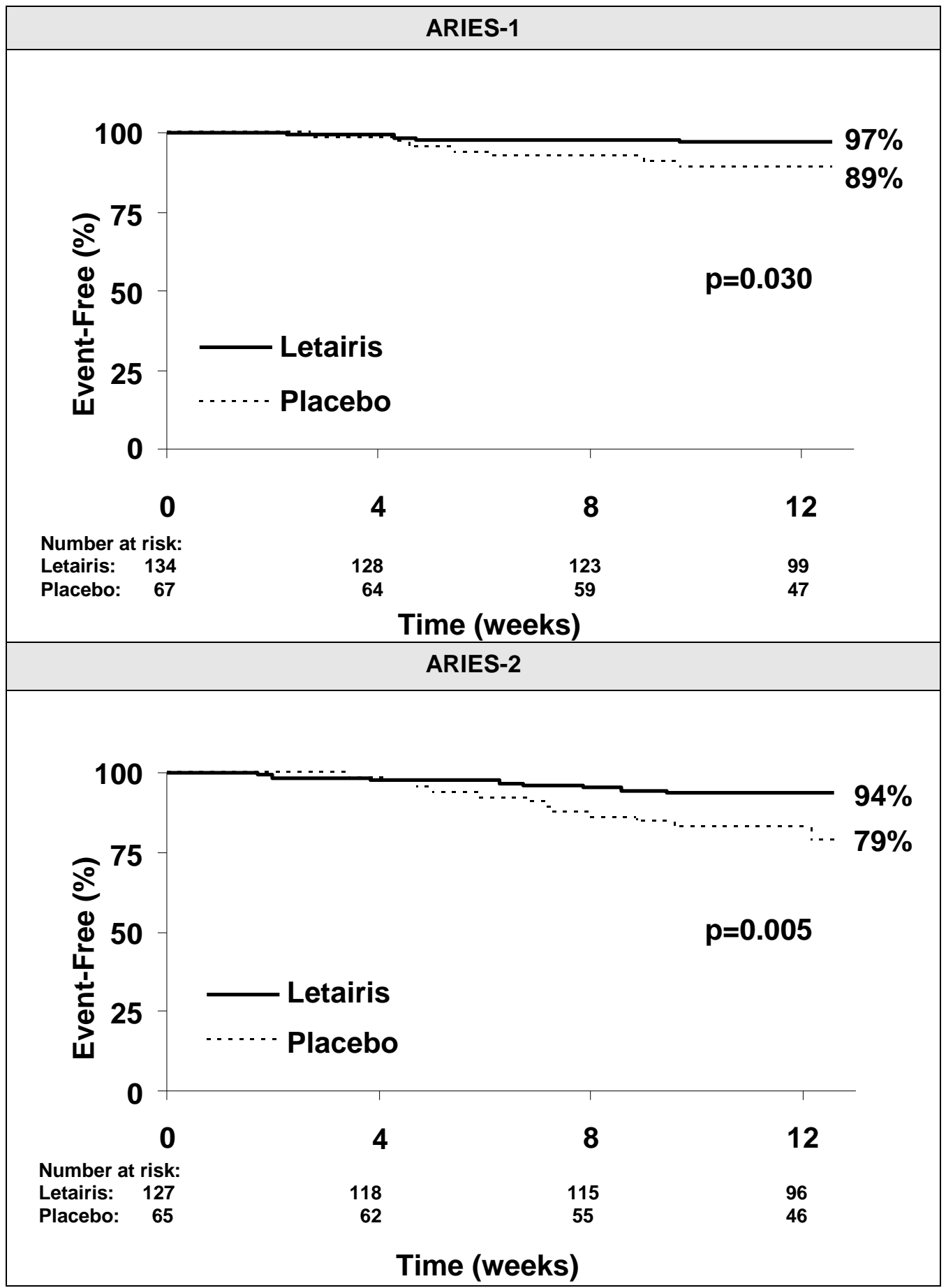

Time from randomization to clinical worsening with Kaplan-Meier estimates of the proportions of patients without events in ARIES-1 and ARIES-2.

p-values shown are the log-rank comparisons of Letairis to placebo stratified by idiopathic or heritable $\mathrm{PAH}$ and non-idiopathic, non-heritable $\mathrm{PAH}$ patients.

\subsection{Combination Treatment of PAH}

In a randomized, double-blind, active-controlled trial (AMBITION), 605 patients with WHO Functional Class II or III PAH were randomized 2:1:1 to once daily Letairis plus tadalafil or to Letairis or tadalafil alone. Treatment was initiated with Letairis $5 \mathrm{mg}$ and tadalafil $20 \mathrm{mg}$. If tolerated, tadalafil was increased to $40 \mathrm{mg}$ at 4 weeks and Letairis was increased to $10 \mathrm{mg}$ at 8 weeks. 
The primary endpoint was time to first occurrence of (a) death, (b) hospitalization for worsening PAH, (c) $>15 \%$ decrease from baseline in 6MWD combined with WHO Functional Class III or IV symptoms sustained over 14 days (short term clinical worsening), or (d) reduction in 6MWD sustained over 14 days combined with WHO Functional Class III or IV symptoms sustained over 6 months (inadequate long term clinical response).

Patients had idiopathic PAH (55\%), heritable PAH (3\%), or PAH associated with connective tissue diseases, congenital heart disease, stable HIV infection, or drugs or toxins (APAH, 43\%). Median time from diagnosis to first study drug administration was 25 days. Approximately $32 \%$ and $68 \%$ of patients were in WHO Functional Class II and III, respectively. The mean patient age was 55.7 years (34\% were $\geq 65$ years old). Most patients were white (90\%) and female (76\%); $45 \%$ were North American.

Principal results are shown in Figures 6 and 7.

\section{Figure 6 Time to Primary Endpoint Event (AMBITION)}

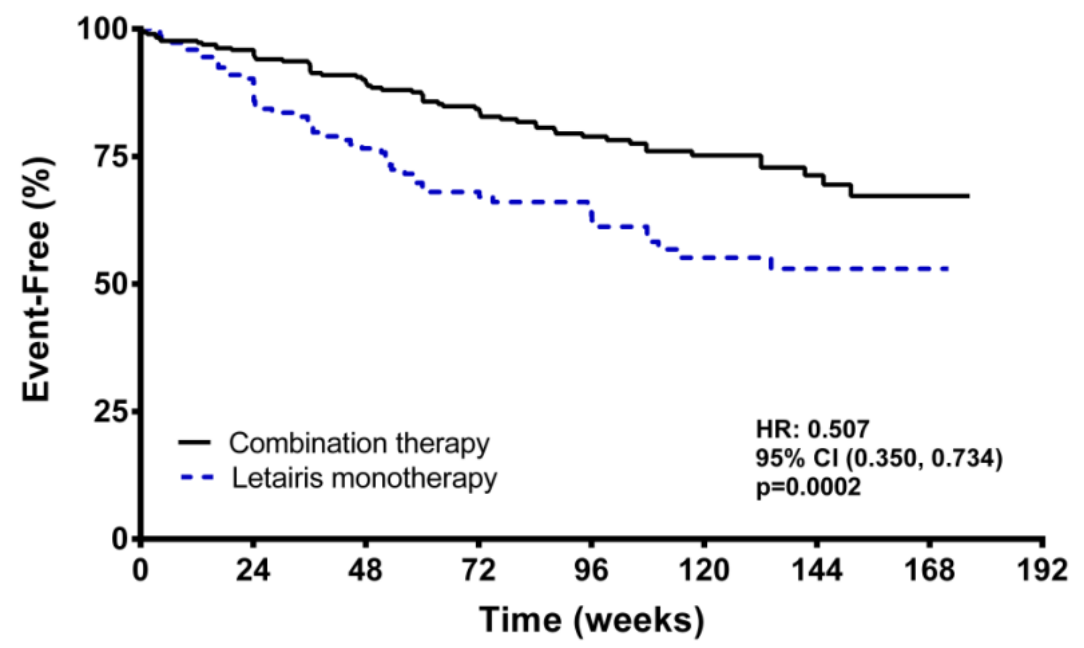

$\begin{array}{lrrrrrrrr}\text { Number at risk: } & & & & & & & \\ \text { Combination: } & 302 & 270 & 217 & 170 & 126 & 85 & 45 & 9 \\ \text { Letairis monotherapy: } & 152 & 123 & 96 & 71 & 53 & 30 & 17 & 3\end{array}$

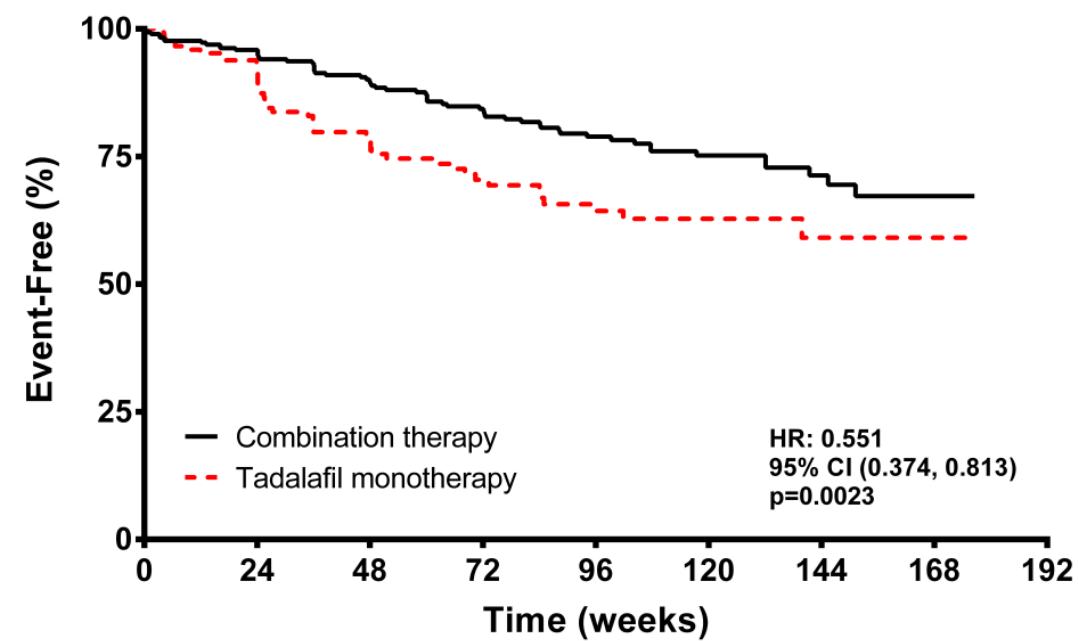

Number at risk:

Combination: $\begin{array}{rrrrrrrr}302 & 270 & 217 & 170 & 126 & 85 & 45 & 9\end{array}$ 
Figure 7 Primary Endpoint Events and First Occurrences of Each Component at Any Time (AMBITION)

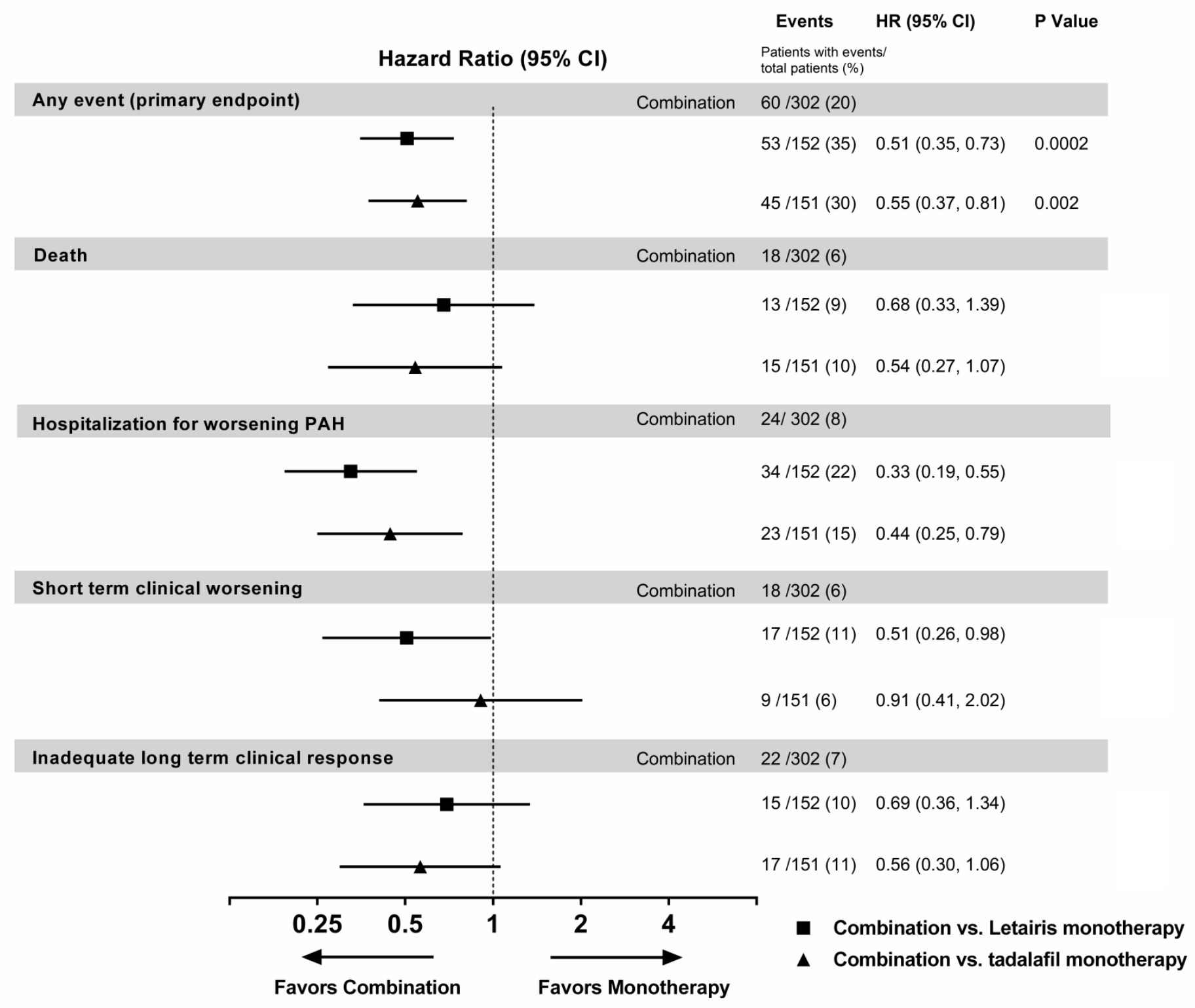

The treatment effect of Letairis plus tadalafil compared with individual monotherapy on time to first primary endpoint event was consistent across subgroups. (Figure 8). 


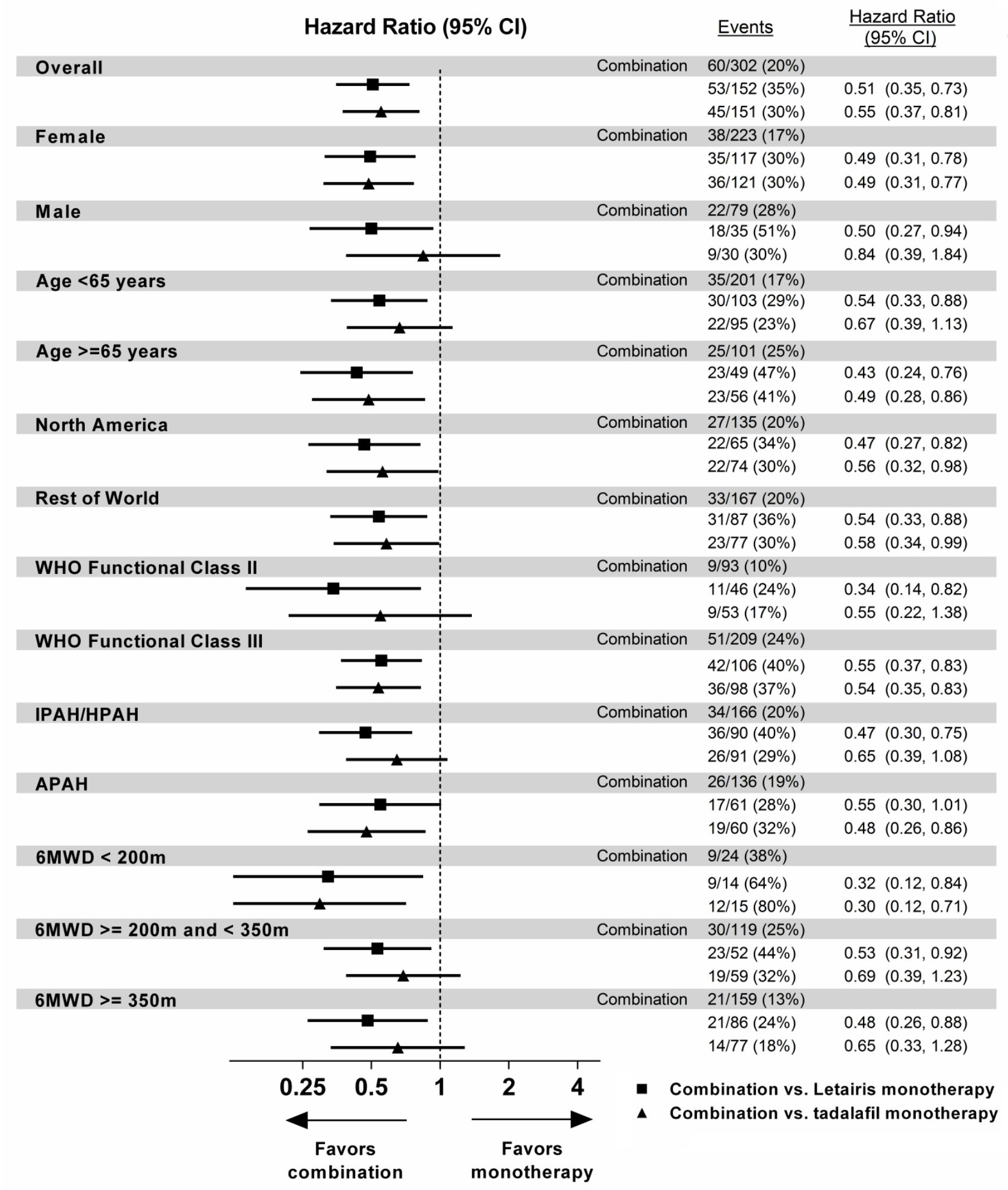

Note: The figure above presents effects in various subgroups all of which are baseline characteristics and all of which were pre-specified, if not the groupings. The $95 \%$ confidence limits that are shown do not take into account how many comparisons were made, nor do they reflect the effect of a particular factor after adjustment for all other factors. Apparent homogeneity or heterogeneity among groups should not be over interpreted. 


\section{Exercise Ability}

Results of the 6MWD at 24 weeks for the AMBITION study are shown in Table 5 and Figure 9.

Table 5

6-Minute Walk Distance at Week 24 (meters) ${ }^{\mathrm{a}}$ (AMBITION)

\begin{tabular}{|l|c|c|c|}
\hline & $\begin{array}{c}\text { Letairis + } \\
\text { Tadalafil } \\
(\mathbf{N = 3 0 2})\end{array}$ & $\begin{array}{c}\text { Letairis } \\
\text { Monotherapy } \\
(\mathbf{N = 1 5 2 )}\end{array}$ & $\begin{array}{c}\text { Tadalafil } \\
\text { Monotherapy } \\
(\mathbf{N}=\mathbf{1 5 1})\end{array}$ \\
\hline Baseline (median) & 356 & 366 & 352 \\
\hline $\begin{array}{l}\text { Change from baseline } \\
\text { (median) }\end{array}$ & 43 & 23 & 22 \\
\hline $\begin{array}{l}\text { Median difference from } \\
\text { Letairis + Tadalafil } \\
\text { (95\% Cl) }\end{array}$ & & 24 & 20 \\
\hline P-Value & & 0.0004 & 0.0016 \\
\hline
\end{tabular}

a Missing values at Week 24 were imputed using Worst Rank scores for patients with an adjudicated clinical failure event of death or hospitalization, and Last Observed Carried Forward otherwise.

Figure 9 Median Change in 6-Minute Walk Distance (meters) in AMBITION

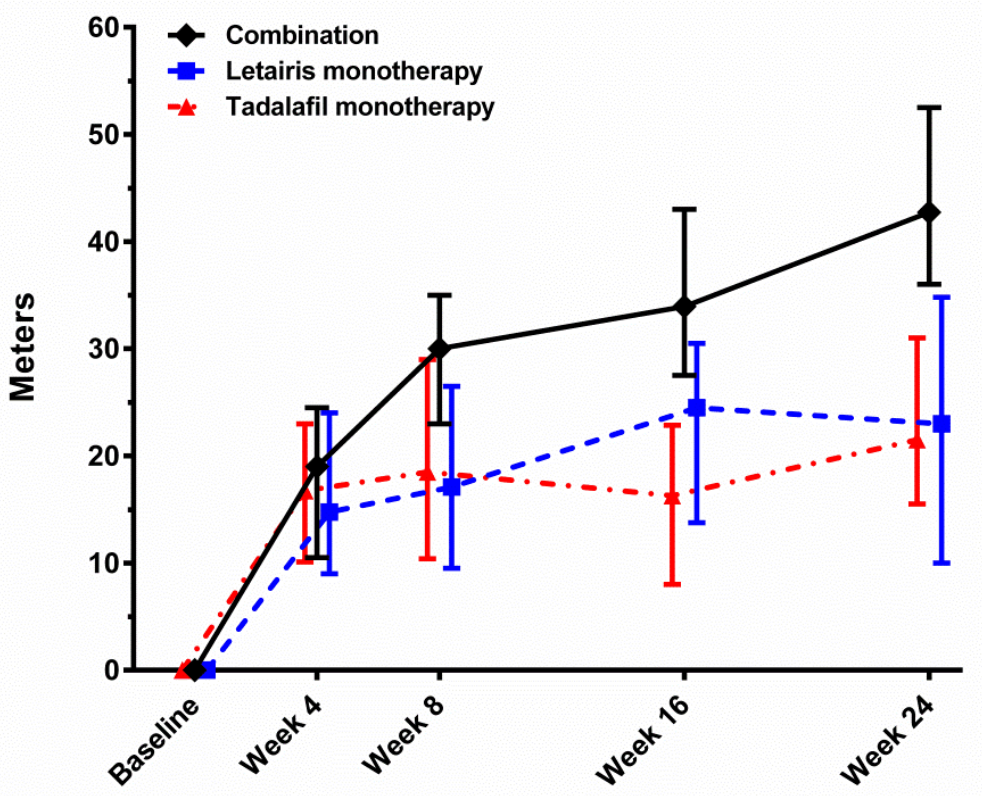

Error bars represent $95 \%$ confidence intervals

\subsection{Long-term Treatment of PAH}

In long-term follow-up of patients who were treated with Letairis $(2.5 \mathrm{mg}, 5 \mathrm{mg}$, or $10 \mathrm{mg}$ once daily) in the two pivotal studies and their open-label extension ( $\mathrm{N}=383)$, Kaplan-Meier estimates of survival at 1,2 , and 3 years were $93 \%, 85 \%$, and $79 \%$, respectively. Of the patients who remained on Letairis for up to 3 years, the majority received no other treatment for $\mathrm{PAH}$. These uncontrolled observations do not allow comparison with a group not given Letairis and cannot be used to determine the long-term effect of Letairis on mortality. 


\subsection{Adverse Effects in Idiopathic Pulmonary Fibrosis (IPF)}

A randomized controlled study in patients with IPF, with or without pulmonary hypertension (WHO Group 3), compared Letairis $(\mathrm{N}=329)$ to placebo $(\mathrm{N}=163)$. The study was terminated after 34 weeks for lack of efficacy, and was found to demonstrate a greater risk of disease progression or death on Letairis. More patients taking Letairis died ( $8 \%$ vs. $4 \%$ ), had a respiratory hospitalization ( $13 \%$ vs. $6 \%)$, and had a decrease in FVC/DLCO (17\% vs. 12\%) [see Contraindications (4.2)].

\section{HOW SUPPLIED/STORAGE AND HANDLING}

Letairis film-coated tablets are supplied as follows:

\begin{tabular}{|c|c|c|c|}
\hline Tablet Strength & $\begin{array}{c}\text { Package } \\
\text { Configuration }\end{array}$ & NDC No. & $\begin{array}{l}\text { Description of Tablet; } \\
\text { Debossed on Tablet; } \\
\text { Size }\end{array}$ \\
\hline \multirow{4}{*}{$5 \mathrm{mg}$} & 30 count blister & $61958-0801-2$ & \multirow{4}{*}{$\begin{array}{l}\text { Square convex; pale pink; } \\
\text { "5" on side } 1 \text { and "GSI" on side 2; } \\
6.6 \mathrm{~mm} \text { Square }\end{array}$} \\
\hline & 30 count bottle & 61958-0801-1 & \\
\hline & 10 count blister & $61958-0801-3$ & \\
\hline & 10 count bottle & $61958-0801-5$ & \\
\hline \multirow{4}{*}{$10 \mathrm{mg}$} & 30 count blister & $61958-0802-2$ & \multirow{4}{*}{$\begin{array}{l}\text { Oval convex; deep pink; } \\
\text { "10" on side } 1 \text { and "GSI" on side } 2 \text {; } \\
9.8 \mathrm{~mm} \text { x } 4.9 \mathrm{~mm} \text { Oval }\end{array}$} \\
\hline & 30 count bottle & $61958-0802-1$ & \\
\hline & 10 count blister & $61958-0802-3$ & \\
\hline & 10 count bottle & $61958-0802-5$ & \\
\hline
\end{tabular}

Store at $25^{\circ} \mathrm{C}\left(77^{\circ} \mathrm{F}\right)$; excursions permitted to $15-30^{\circ} \mathrm{C}\left(59-86^{\circ} \mathrm{F}\right)$ [see USP controlled room temperature]. Store Letairis in its original packaging.

\section{PATIENT COUNSELING INFORMATION}

Advise patients to read the FDA-approved patient labeling (Medication Guide).

\section{Embryo-fetal Toxicity}

Instruct patients on the risk of fetal harm when Letairis is used in pregnancy [see Warnings and Precautions (5.1) and Use in Specific Populations (8.1)]. Female patients must enroll in the Ambrisentan REMS. Instruct females of reproductive potential to immediately contact their physician if they suspect they may be pregnant.

\section{Ambrisentan Risk Evaluation and Mitigation Strategy (REMS)}

For female patients, Letairis is only available through a restricted program called the Ambrisentan REMS [see Contraindications (4.1), Warnings and Precautions (5.2)]. Male patients are not enrolled in the Ambrisentan REMS.

Inform female patients (and their guardians, if applicable) of the following notable requirements:

- All female patients must sign an enrollment form.

- Female patients of reproductive potential must comply with the pregnancy testing and contraception requirements [see Use in Specific Populations (8.3)]. 
- Females of reproductive potential must be counseled on the use of emergency contraception in the event of unprotected sex or known or suspected contraceptive failure.

- Pre-pubertal females must report any changes in their reproductive status immediately to their prescriber.

Letairis is available only from certified pharmacies participating in the program. Therefore, provide patients with the telephone number and website for information on how to obtain the product.

\section{Hepatic Effects}

Advise patients of the symptoms of potential liver injury and instruct them to report any of these symptoms to their physician.

\section{Hematological Change}

Advise patients of the importance of hemoglobin testing.

\section{Other Risks Associated with Letairis}

Instruct patients that the risks associated with Letairis also include the following:

- Decreases in sperm count

- Fluid overload

\section{Administration}

Advise patients not to split, crush, or chew tablets.

Gilead Sciences, Inc., Foster City, CA 94404

Letairis is a registered trademark of Gilead Sciences, Inc. Gilead and the Gilead logo are trademarks of Gilead Sciences, Inc. Other brands noted herein are the property of their respective owners.

(C) 2019 Gilead Sciences, Inc.

GS22-081-017 


\section{Medication Guide \\ Letairis $^{\circledR}$ (le-TAIR-is) \\ (ambrisentan) Tablets}

Read this Medication Guide before you start taking Letairis and each time you get a refill. There may be new information. This Medication Guide does not take the place of talking with your doctor about your medical condition or your treatment.

\section{What is the most important information I should know about Letairis?}

- Serious birth defects.

Letairis can cause serious birth defects if taken during pregnancy.

o Females must not be pregnant when they start taking Letairis or become pregnant during treatment with Letairis.

- Females who are able to get pregnant must have a negative pregnancy test before beginning treatment with Letairis, each month during treatment with Letairis, and one month after stopping Letairis. Talk to your doctor about your menstrual cycle. Your doctor will decide when to do a pregnancy test, and will order a pregnancy test for you depending on your menstrual cycle.

- Females who are able to get pregnant are females who:

- have entered puberty, even if they have not started their menstrual period, and

- have a uterus, and

- have not gone through menopause. Menopause means that you have not had a menstrual period for at least 12 months for natural reasons, or that you have had your ovaries removed.

- Females who are not able to get pregnant are females who:

- have not yet entered puberty, or

- do not have a uterus, or

- have gone through menopause. Menopause means that you have not had a menstrual period for at least 12 months for natural reasons, or that you have had your ovaries removed, or

- who are infertile for any other medical reason and this infertility is permanent and cannot be reversed

Females who are able to get pregnant must use two acceptable forms of birth control during treatment with Letairis, and for one month after stopping Letairis because the medicine may still be in the body.

o If you have had a tubal sterilization or have an IUD (intrauterine device) or progesterone implant, these methods can be used alone and no other form of birth control is needed.

- Talk with your doctor or gynecologist (a doctor who specializes in female reproduction) to find out about options for acceptable forms of birth control that you may use to prevent pregnancy during treatment with Letairis.

o If you decide that you want to change the form of birth control that you use, talk with your doctor or gynecologist to be sure that you choose another acceptable form of birth control.

See the chart below for Acceptable Birth Control Options during treatment with Letairis.

\section{Acceptable Birth Control Options}

Option 1

One method from this list:

Standard intrauterine device (Copper T 380A IUD)

Intrauterine system

(LNg 20 IUS - progesterone IUD)

Tubal sterilization

Progesterone implant

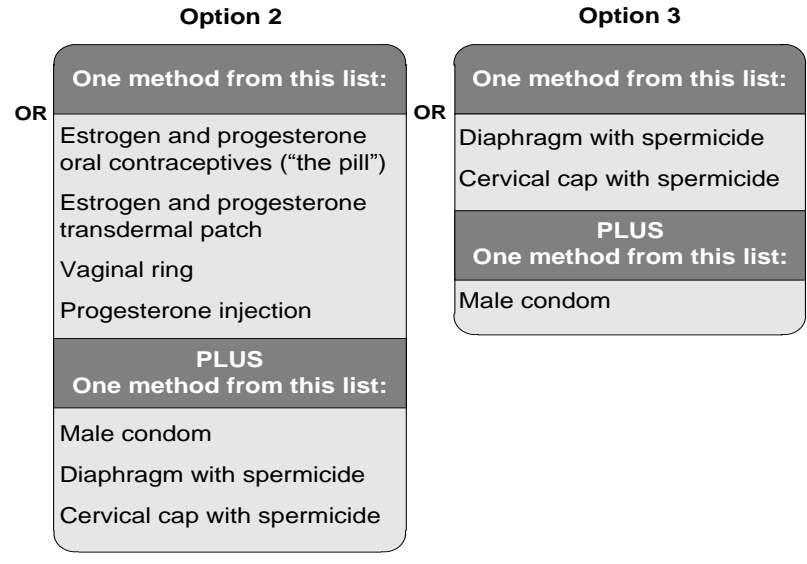

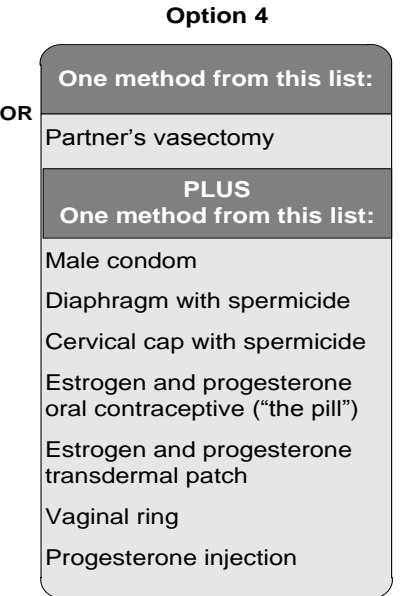

- Do not have unprotected sex. Talk to your doctor or pharmacist right away if you have unprotected sex or if you think your birth control has failed. Your doctor may tell you to use emergency birth control.

- Tell your doctor right away if you miss a menstrual period or think you may be pregnant for any reason.

If you are the parent or caregiver of a female child who started taking Letairis before reaching puberty, you should check 
your child regularly to see if she is developing signs of puberty. Tell your doctor right away if you notice that she is developing breast buds or pubic hair. Your doctor should decide if your child has reached puberty. Your child may reach puberty before having her first menstrual period.

Females can only receive Letairis through a restricted program under a Risk Evaluation and Mitigation Strategy (REMS) called the Ambrisentan REMS. If you are a female who can get pregnant, you must talk to your doctor, understand the benefits and risks of Letairis, and agree to all of the instructions in the Ambrisentan REMS.

Males can receive Letairis without taking part in the Ambrisentan REMS.

What is Letairis?

- Letairis is a prescription medicine used to treat pulmonary arterial hypertension (PAH), which is high blood pressure in the arteries of your lungs.

- Letairis can improve your ability to exercise and it can help slow down the worsening of your physical condition and symptoms.

- When taken with tadalafil, Letairis is used to reduce the risk of your disease progressing, to reduce the risk of hospitalization due to worsening pulmonary arterial hypertension (PAH), and to improve your ability to exercise.

- It is not known if Letairis is safe and effective in children.

Who should not take Letairis?

Do not take Letairis if:

- you are pregnant, plan to become pregnant, or become pregnant during treatment with Letairis. Letairis can cause serious birth defects. (See "What is the most important information I should know about Letairis?") Serious birth defects from Letairis happen early in pregnancy.

- you have a condition called Idiopathic Pulmonary Fibrosis (IPF)

What should I tell my doctor before taking Letairis?

Before you take Letairis, tell your doctor if you:

- have been told that you have a low red blood cell level (anemia)

- have liver problems

- have any other medical conditions

Tell your doctor about all the medicines you take, including prescription and over-the-counter medicines, vitamins, and herbal supplements. Letairis and other medicines may affect each other, causing side effects. Do not start any new medicines until you check with your doctor.

Especially tell your doctor if you take the medicine cyclosporine (Gengraf, Neoral, Sandimmune). Your doctor may need to change your dose of Letairis.

How should I take Letairis?

- Letairis will be mailed to you by a certified pharmacy. Your doctor will give you complete details.

- Take Letairis exactly as your doctor tells you to take it. Do not stop taking Letairis unless your doctor tells you to stop.

- You can take Letairis with or without food.

- Do not split, crush or chew Letairis tablets.

- It will be easier to remember to take Letairis if you take it at the same time each day.

- If you take more than your regular dose of Letairis, call your doctor right away.

- If you miss a dose, take it as soon as you remember that day. Take your next dose at the regular time. Do not take two doses at the same time to make up for a missed dose.

What should I avoid while taking Letairis?

- Do not get pregnant while taking Letairis. (See the serious birth defects section of the Medication Guide above called "What is the most important information I should know about Letairis?") If you miss a menstrual period, or think you might be pregnant, call your doctor right away.

- It is not known if Letairis passes into your breast milk. You should not breastfeed if you are taking Letairis. Talk to your doctor about the best way to feed your baby if you take Letairis.

What are the possible side effects of Letairis?

Letairis can cause serious side effects including:

- See "What is the most important information I should know about Letairis?"

- Swelling all over the body (fluid retention) can happen within weeks after starting Letairis. Tell your doctor right away if you have any unusual weight gain, tiredness, or trouble breathing while taking Letairis. These may be symptoms of a serious health problem. You may need to be treated with medicine or need to go to the hospital.

- Decreased sperm count. Decreased sperm counts have happened in some men taking a medicine that is like Letairis. A decreased sperm count may affect the ability to father a child. Tell your doctor if being able to have children is important to you. 
- Low red blood cell levels (anemia) can happen during the first weeks after starting Letairis. If this happens, you may need a blood transfusion. Your doctor will do blood tests to check your red blood cells before starting Letairis. Your doctor may also do these tests during treatment with Letairis.

The most common side effects of Letairis include:

- swelling of hands, legs, ankles and feet (peripheral

- inflamed nasal passages (sinusitis) edema)

- hot flashes or getting red in the face (flushing)

- stuffy nose (nasal congestion)

Some medicines that are like Letairis can cause liver problems. Tell your doctor if you get any of these symptoms of a liver problem while taking Letairis:

- loss of appetite

- nausea or vomiting

- fever

- achiness

- generally do not feel well

- pain in the upper right stomach (abdominal) area

- yellowing of your skin or the whites of your eyes

- dark urine

- itching

Tell your doctor if you have any side effect that bothers you or that does not go away. These are not all of the possible side effects of Letairis. For more information, ask your doctor or pharmacist.

Call your doctor for medical advice about side effects. You may report side effects to FDA at 1-800-FDA-1088.

How should I store Letairis?

Store Letairis at room temperature between $68^{\circ} \mathrm{F}$ to $77^{\circ} \mathrm{F}\left(20^{\circ} \mathrm{C}\right.$ to $\left.25^{\circ} \mathrm{C}\right)$, in the package it comes in.

Keep Letairis and all medicines out of the reach of children.

General information about the safe and effective use of Letairis

Medicines are sometimes prescribed for purposes other than those listed in a Medication Guide. Do not use Letairis for a condition for which it was not prescribed. Do not give Letairis to other people, even if they have the same symptoms that you have. It may harm them.

This Medication Guide summarizes the most important information about Letairis. If you would like more information, ask your doctor. You can ask your doctor or pharmacist for information about Letairis that is written for health professionals.

What are the ingredients in Letairis?

Active ingredient: ambrisentan

Inactive Ingredients: croscarmellose sodium, lactose monohydrate, magnesium stearate and microcrystalline cellulose.

The tablets are film-coated with a coating material containing FD\&C Red \#40 aluminum lake, lecithin, polyethylene

glycol, polyvinyl alcohol, talc, and titanium dioxide.

Gilead Sciences, Inc., Foster City, CA 94404

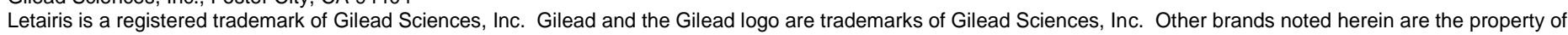
their respective owners.

(C) 2019 Gilead Sciences, Inc.

GS22-081-017

For more information call 1-866-664-5327 or go to www.letairis.com or www.gilead.com

This Medication Guide has been approved by the U.S. Food and Drug Administration.

Revised August 2019 